\title{
The Effect of Enamel Matrix Protein Derivative on Follicle Cells In Vitro
}

Sema S. Hakki, * Janice E. Berry, ${ }^{*}$ and Martha J. Somerman * ${ }^{\dagger}$

Background: It is thought that during development of the periodontium, dental follicle cells, when appropriately triggered, have the ability to differentiate into periodontal ligament fibroblasts, cementoblasts, and osteoblasts. However, the exact mechanisms/factors responsible for initiating cell differentiation are not defined. The purpose of this in vitro study was to further characterize follicle cells and to determine the effects of an enamel matrix-derived protein (EMD) on these cells.

Methods: Murine follicle cells, transformed with simian virus 40 (SV 40) T antigen-containing virus (SVF cells), were used. SVF cells were cultured in Dulbecco's modified Eagle's medium (DMEM) plus $2 \%$ fetal bovine serum (FBS) or $2 \%$ FBS plus EMD $(100 \mu \mathrm{g} / \mathrm{ml})$, with and without ascorbic acid $(50 \mu \mathrm{g} / \mathrm{ml})$. For proliferation assays, cells were plated at $500 \mathrm{cells} / \mathrm{cm}^{2}$ in 24 well plates and counted on days 3, 4, and 5. For Northern analysis, total RNA was isolated on days 8,12 , and 18. Induction of mineral nodules by SVF cells was determined by von Kossa staining.

Results: EMD had a significant proliferative effect on SVF cells, when compared with $2 \%$ FBS control. Based on investigations in situ, follicle cells at the time point used here do not express key mineral-associated markers, e.g., osteocalcin (OCN) or bone sialoprotein (BSP). Significantly, by day 12 in culture, Northern analysis indicated that the follicle cells expressed transcripts for BSP, OCN, and osteopontin (OPN). EMD increased OPN mRNA and decreased OCN mRNA expression. SVF cells were capable of inducing mineralization on day 18, but EMD blocked this activity.

Conclusions: These results suggest the follicle cells have the capacity to act as cementoblasts or osteoblasts. Furthermore, EMD can regulate follicle cell activity, thus suggesting that epithelial-mesenchymal interactions may be important during development of periodontal tissues. J Periodontol 2001;72:679-687.

\section{KEY WORDS}

Dental follicle; cell differentiation; protein, enamel matrix.

\footnotetext{
* Department of Periodontics/Prevention/Geriatrics, University of Michigan, School of Dentistry, Ann Arbor, MI.

$\dagger$ Department of Pharmacology, School of Medicine.
}

T The dental follicle, a loose connective tissue surrounding the unerupted tooth, is required for eruption to occur. ${ }^{1-5}$ Beyond their critical role during tooth eruption, follicle cells are also thought to have the ability to differentiate into periodontal cells (cementoblasts, periodontal ligament fibroblasts, and osteoblasts) as required for development of the periodontium. ${ }^{6}$ However, the specific events, mechanisms, and factors controlling follicle cell activities during tooth eruption and periodontal tissue formation remain undefined. The studies here focused on determining the potential regulators of follicle cell maturation toward a "cementoblast-osteoblast" phenotype.

Identifying specific factors and/or mechanisms regulating development of periodontal tissues will provide important information as to which molecules and cells are required for regeneration of periodontal tissues lost as a consequence of disease. To date, several candidate cells and associated factors have been identified, although their specific role in controlling periodontal formation has not been confirmed. ${ }^{7,8}$ Results from some studies suggest, in a similar fashion to enamel-dentin formation, ${ }^{9}$ that epithelial-mesenchymal interactions are required for follicle cells to function as cementoblasts, osteoblasts, or periodontal ligament cells. ${ }^{10,11}$ For example, it has been proposed that proteins derived from enamel, e.g., amelogenin and/or ameloblastin, may be involved in regulating follicle cell maturation and/or transformation of epithelial root sheath (ERS) cells into cementoblasts. ${ }^{12,13}$ 
In the studies here, we focused on the role of $\mathrm{EMD}^{\ddagger}$ in controlling follicle cell behavior. EMD is a novel therapeutic agent intended to promote regeneration of periodontal tissues. EMD has been reported to contain a protein complex belonging to the amelogenin family. ${ }^{14}$ Amelogenins are extracellular matrix components of enamel which are considered by some to play an important role in enamel mineralization. ${ }^{15-17}$ Studies to date have reported that EMD has the capacity to induce proliferation, migration, adhesion, mineralization, and differentiation of cells, which are all events involved in periodontal regeneration and healing. ${ }^{18,19}$ Heijl and colleagues reported that EMD was effective in the treatment of intrabony defects in humans. ${ }^{20,21}$ Further studies, using EMD with and without barrier membranes, have reported that EMD enhanced connective tissue attachment and wound healing. ${ }^{22-25}$ In addition, Hammarström and coworkers, using a monkey model, demonstrated that EMD enhanced formation of bone, cementum, and periodontal ligament. ${ }^{26}$ In vitro studies suggest that EMD can enhance the synthesis of transforming growth factor- $\beta$ in periodontal ligament (PDL) cells ${ }^{27}$ and that this secondary effect may, in part, explain some of the activities attributed to EMD.

These studies suggest a positive role for EMD in promoting cell activities as required during periodontal wound healing. A major rationale indicated for using EMD clinically is based on the hypothesis that epithelial-mesenchymal interactions are required for maturation of the developing periodontium and hence for regeneration of periodontal tissues. To further define the role of EMD in regulating mesenchymal cells, we focused on determining the effects of EMD on the putative precursor cells of osteoblasts, cementoblasts, and PDL fibroblasts; i.e., follicle cells.

\section{MATERIALS AND METHODS}

\section{Cell Culture}

Follicle cells were obtained from CD-1 mice at day 22 of development, where day 0 is defined as vaginal plug date and mice are usually born on day 19. Selection of this time point for isolation of follicle cells was based on in situ data ${ }^{28,29}$ indicating that at this time, cells within the local region do not express BSP or OCN, and root formation (cementogenesis) has not been initiated. The method used for cell isolation was similar to that previously reported by Wise et al. ${ }^{1}$ Briefly, using a dissecting microscope, first molars were removed and then subjected to enzymatic digestion (collagenase type VII $0.6 \mathrm{mg} / \mathrm{ml}$ trypsin $0.25 \%$ ) $\S$ for 1 hour. To immortalize cells following enzymatic digestion, cells were resuspended in $25 \mathrm{ml}$ Dulbecco's modified Eagle's medium (DMEM) $)^{\|}$containing $2 \%$ fetal bovine serum (FBS) and simian virus 40 (SV40) at a multiplicity of infection of 100 . Epithelial cells did not sur- vive in this media, as determined by lack of expression for specific keratins" (data not shown). After infecting for 2 hours in suspension, cells were plated with an equal volume of media containing $20 \%$ FBS. Media were removed the next day and replaced with DMEM containing $10 \%$ FBS. To confirm infection with virus, expression of SV40 TAg was determined by Northern analysis, using a large T-antigen probe (mouse osteocalcin promoter driven $\mathrm{T}$-antigen in $\mathrm{p}(\mathrm{UC})$ obtained from Dr. Jolene Windle. ${ }^{30}$ Cells were subsequently screened for TAg by immunohistochemistry using a polyclonal antibody to SV40 large T antigen\# ${ }^{\#}$ detected with a peroxidase kit, " and were found to be uniformly positive (data not shown). Infected follicle cells were named SVF cells, and were maintained in DMEM plus $10 \%$ FBS containing $100 \mathrm{U} / \mathrm{ml}$ of penicillin ${ }^{\|}$and 100 $\mu \mathrm{g} / \mathrm{ml}$ streptomycin ${ }^{\|}$in a humidified atmosphere of $5 \%$ $\mathrm{CO}_{2}$ at $37^{\circ} \mathrm{C}$.

\section{Enamel Matrix Protein}

EMD was generously provided by the manufacturer. ${ }^{\dagger}$ The dose selected for the studies reported here was based on our previous investigations with cementoblasts and osteoblasts, where EMD at $100 \mu \mathrm{g} / \mathrm{ml}$ altered both cell proliferation and gene expression. ${ }^{31}$

\section{Cell Proliferation}

Follicle cells were plated at 500 cells $/ \mathrm{cm}^{2}$ in triplicate wells of 24 -well dishes in DMEM with $10 \%$ FBS and allowed to adhere overnight. On the following day, media were changed and cells treated with: $2 \%$ FBS or $2 \%$ FBS + EMD $(100 \mu \mathrm{g} / \mathrm{ml})$, with and without ascorbic acid $(50 \mu \mathrm{g} / \mathrm{ml})$. For proliferation assays, cells were harvested on days 3, 4, and 5 using trypsin/EDTA and cell number determined using a Coulter counter. Experiments were repeated 2 times.

\section{Morphology}

A microscope** was used to take images of follicle cells on days 8,12 , and 15 .

\section{Northern Blot Analysis}

To determine gene expression, follicle cells were plated in $100 \mathrm{~mm}$ cell culture dishes ${ }^{\dagger \dagger}$ at 5,000 cells/dish. Cells were allowed to adhere for 24 hours in DMEM with $10 \%$ FBS, after which media were changed to DMEM with $2 \%$ FBS with $100 \mu \mathrm{g} / \mathrm{ml}$ EMD, \pm ascorbic acid (AA, $50 \mu \mathrm{g} / \mathrm{ml})$. Media with $2 \%$ FBS served as a control. Total RNA was isolated on days 8,12 , and 18 with Trizol $\|$ and RNA concentration quantified by spectrophotometer. RNA ( $5 \mu \mathrm{g})$ was denatured, fractionated

\footnotetext{
* Emdogain, Biora AB, Malmö, Sweden.

$\S$ Sigma Chemical Co., St. Louis, MO.

II Gibco BRL, Gaithersburg, MD.

I Dako Corporation, Carpinteria, CA.

\# PharMingen, San Diego, CA.

** Axiovert 35, Carl Zeiss, Inc., Thornwood, NY.

$\dagger \dagger$ Falcon, Becton Dickinson, Franklin Lakes, NJ.
} 
on a $6 \%$ formaldehyde, $1.2 \%$ agarose gel and transferred to nylon membrane ${ }^{\text {必 }}$ and crosslinked by UV radiation. ${ }^{\neq} \neq$

Blots were hybridized with random primed ${ }^{32} \mathrm{P}$ labeled probes $\S \S$ and exposed to film with intensifying screens at $-70^{\circ} \mathrm{C}$ for 24 to 48 hours. Probes used for Northern blots were BSP $=M$ BSP consisting of $1 \mathrm{~kb}$ of mouse cDNA in PCR $\mathrm{II}^{32}$ (a gift from Drs. M. Young and L. Fisher, NIDCR/NIH, Bethesda, Maryland); OPN = MOP3 consisting of $1 \mathrm{~kb}$ of mouse OPN cDNA in PCR II $^{33}$ (a gift from Drs. M. Young and L. Fisher); and OCN $=400 \mathrm{bp}$ of mouse OCN cDNA originally cloned into pSP65 cloning vector was transferred to Bluescript $\mathrm{SK}^{34}$ (obtained from Dr. J. Wozney, Genetic Institute, Cambridge, Massachusetts). Experiments were carried out two times. An image analysis program ${ }^{\|\|}$ was used to quantify data.

\section{Mineralization Assay}

Cells were plated at 1,000 cells/ well in 24-well plates in DMEM containing $10 \%$ FBS. After 24 hours, the media were changed to DMEM with or without $50 \mu \mathrm{g} / \mathrm{ml}$ ascorbic acid (AA), with or without EMD $(100 \mu \mathrm{g} / \mathrm{ml})$, and with $2 \%$ FBS and supplemented with 10 mM $\beta$-glycerophosphate. ${ }^{35,36}$ Biomineralization assays were performed on days $8,12,18$, and 24. Mineralization by SVF cells was determined with von Kossa staining. ${ }^{37}$ Experiments were performed 3 times.

\section{Statistical Analysis}

For the proliferation assay, the statistical analysis used was 1 -way analysis of variance (ANOVA). Tukey Kramer multiple comparison tests also were performed.

\section{RESULTS}

\section{Cell Proliferation}

As shown in Figure 1 and Table 1, increased proliferation was noted in cells treated with ascorbic acid when compared with appropriate controls. Addition of EMD significantly enhanced cell proliferation in the absence or presence of AA. This effect was apparent by day 4 of treatment.

\section{Cell Morphology}

Parallel to enhanced cell proliferation, changes were noted in the morphology of follicle cells with time in culture. Under normal culture conditions, follicle cells exhibit a fibroblastic spindle-shaped morphology, but with increasing days in culture they become cuboidal.

Table I.

* $P<0.001$.

$\dagger$ Not significant.
Proliferation of SVF cells

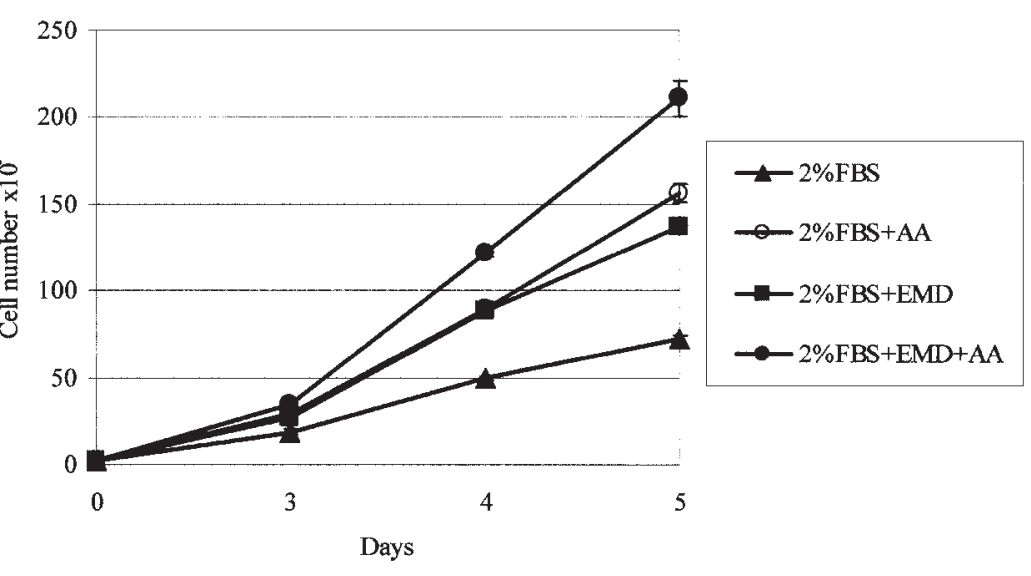

Figure I.

Effect of EMD on follicle cell proliferation. Cells were maintained in media with $2 \%$ FBS $\pm 50 \mu \mathrm{g} / \mathrm{ml}$ ascorbic acid and \pm EMD. The $2 \%$ FBS group was used as a control. Cell number was counted by Coulter counter on days 3, 4, and 5. These results were reproduced in 2 separate experiments.

Statistical Analysis for Figure 1

\begin{tabular}{|c|c|c|c|c|}
\hline & \multicolumn{2}{|c|}{ Day 4} & \multicolumn{2}{|r|}{ Day 5} \\
\hline & $2 \% F B S+E M D$ & $2 \% F B S+E M D+A A$ & $2 \% F B S+E M D$ & $2 \% F B S+E M D+A A$ \\
\hline $2 \%$ FBS & * & * & * & * \\
\hline $2 \% \mathrm{FBS}+\mathrm{AA}$ & $\mathrm{ns}^{\dagger}$ & * & $\mathrm{ns}^{\dagger}$ & * \\
\hline
\end{tabular}

As shown in Figure 2, cells exposed to EMD exhibited this cuboidal appearance at an early time point when compared with cells not exposed to EMD, and this was especially apparent at day 8 in EMD-treated cells without AA as compared to the $2 \%$ FBS control. This cuboidal appearance is similar to what is seen with cementoblasts and osteoblasts. While morphology alone is not necessarily indicative of phenotype, it does distinguish these cells from fibroblastic cells, which tend to maintain an elongated shape in culture even when very confluent.

\section{Northern Analysis}

The next set of experiments was designed to determine whether proliferative and morphological changes elicited by EMD were also reflected in changes in gene expression pattern and in mineral nodule formation by follicle cells.

Day 8. At this time point, follicle cells did not 
Day 8

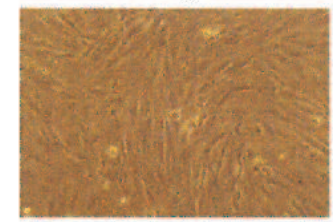

$2 \%$ FBS

\section{$2 \%$ FBS \\ $+\mathrm{AA}$}

$2 \%$ FBS + $E M D+A A$
Day 12
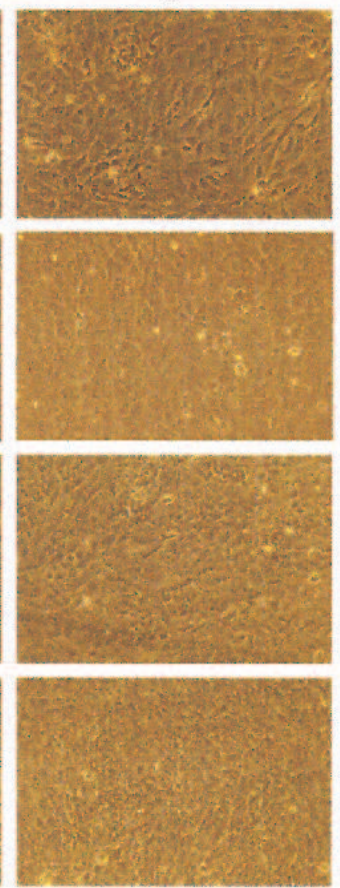

Day 15
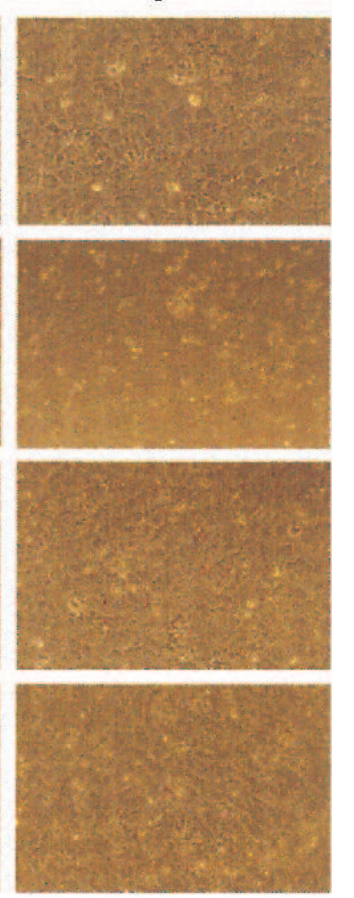

\section{Figure 2.}

Effect of EMD on follicle cell morphology in vitro. For these studies, cells were cultured in media containing $2 \% \mathrm{FBS} \pm 50 \mu \mathrm{g} / \mathrm{ml} A A$ and $\pm 100 \mu \mathrm{g} / \mathrm{ml}$ EMD. Note the increased number of cuboidal cells in EMD groups versus $2 \%$ FBS groups, especially at day 8.

$\mathbf{A}$

\section{Day 8}

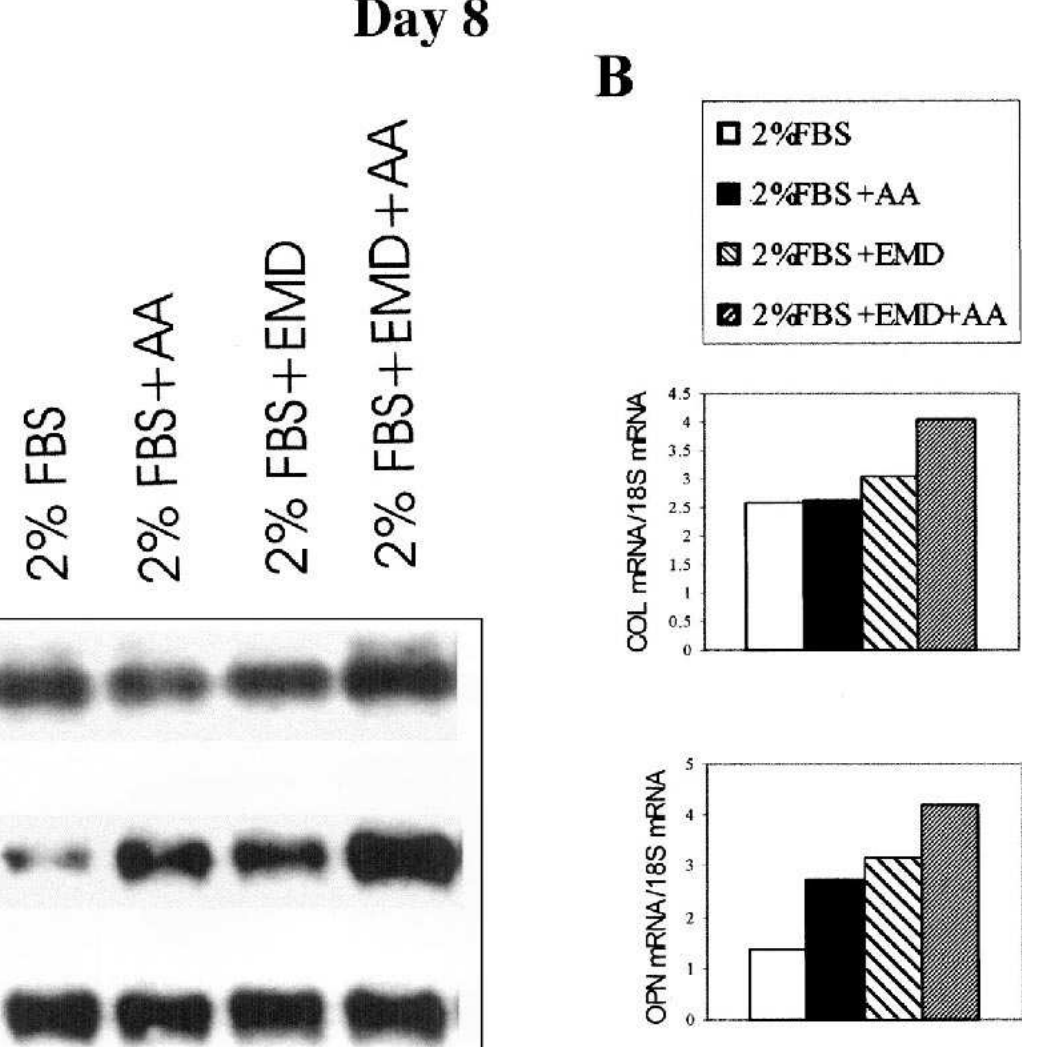

express markers associated with the mature cementoblast/osteoblast phenotype, i.e., BSP and OCN (Fig. 3). EMD-treated cells exhibited enhanced OPN transcripts in the presence and absence of ascorbic acid, when compared to cells not treated with EMD. Also, an increase in collagen expression was noted in cells exposed to EMD, with a more significant effect noted in the EMD plus ascorbic acid group compared to the ascorbic acid group.

Day 12. At day 12, follicle cells, independent of addition of EMD, expressed markers associated with mineralized tissues, e.g., OCN and BSP (Fig. 4). At this time point, the ability of EMD to increase OPN and collagen expression, as seen at day 8, was still observed, but now only noted in the EMD plus AA-treated cells when compared to AA-treated cells. An increased expression of BSP mRNA was observed in cells treated with EMD when compared with appropriate controls. The most dramatic finding was the effect of EMD on OCN expression by follicle cells. EMD almost completely abolished the expression of OCN transcripts in the absence of ascorbic acid. In the presence of ascorbic acid, the ability of EMD to downregulate OCN expression, while still apparent, was not as dramatic.

Day 18. At this time point, cells treated with EMD plus AA retained an enhanced expression of both OPN and collagen mRNAs when com-

Figure 3.

Effect of EMD on gene expression by follicle cells on day 8 . A. Follicle cells were grown in media containing $2 \%$ FBS $\pm A A$ and $\pm E M D$, and RNA isolated at day 8. Gene expression for OPN, collagen type I (COL I), BSP, and OCN was determined by Northern analysis. An I 8S probe was used to evaluate loading efficiency and for normalization. Note increased expression of COL I and OPN in cells exposed to EMD. BSP and OCN transcripts were not apparent at this time point. B. Normalization expressed as gene/ I $8 S$ mRNA. These results were noted in 2 separate experiments ( $Y$ axis: relative value treated/control). 


\section{Day 12}

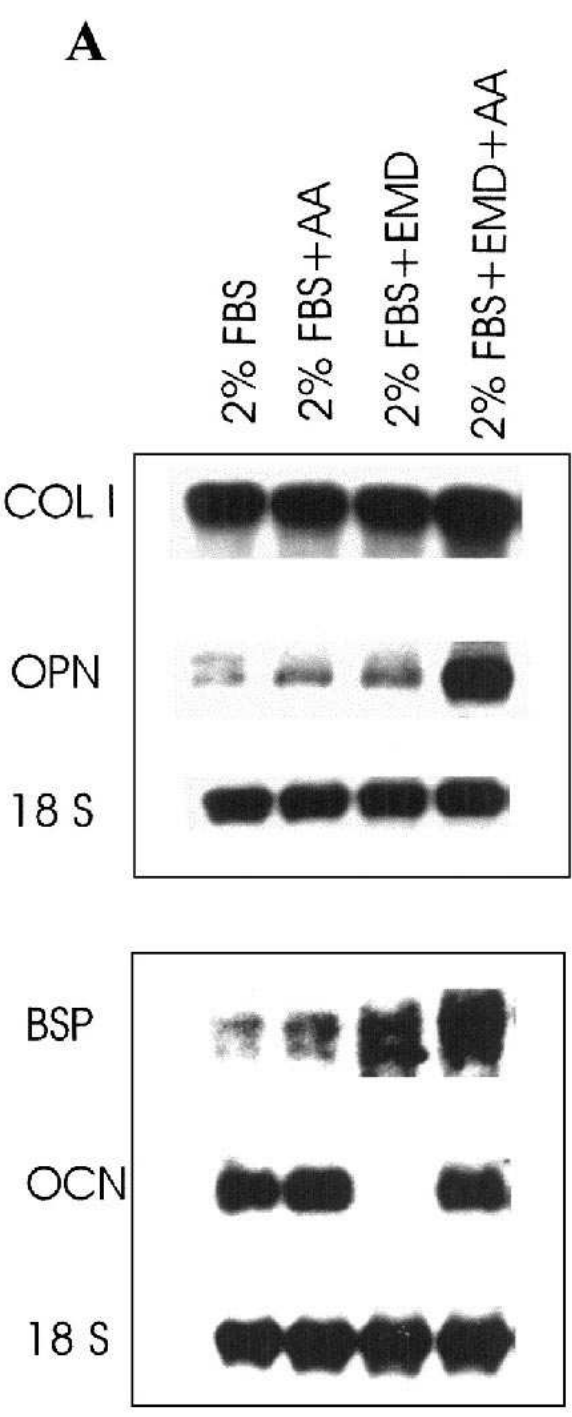

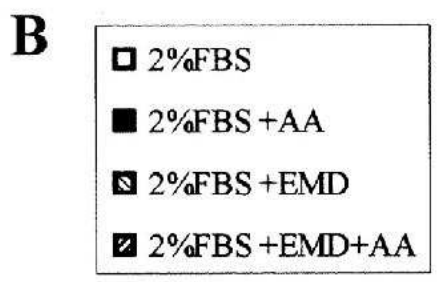
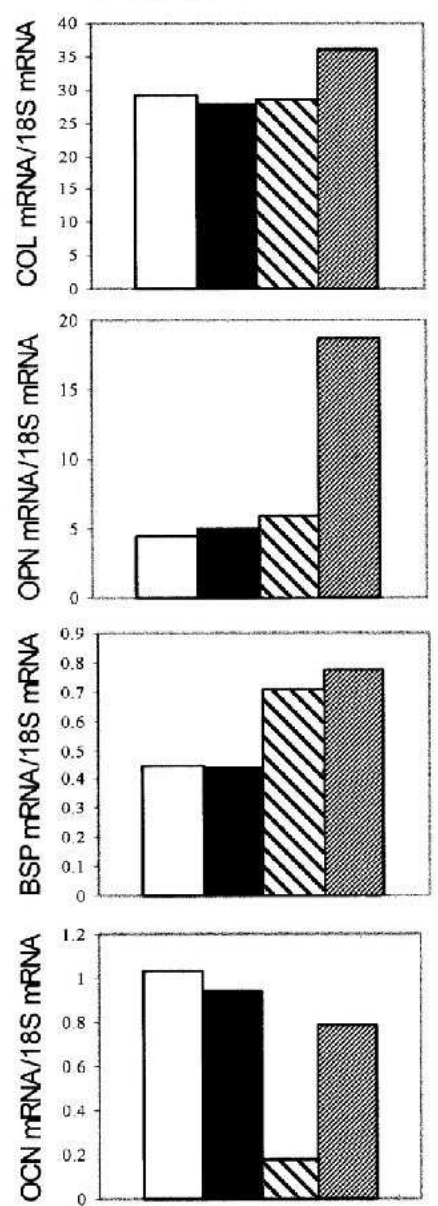

Figure 4.

Effect of EMD on gene expression by follicle cells on day 12. A. Follicle cells were grown in media containing $2 \% F B S \pm A A$ and $\pm E M D$ and RNA isolated at day 12. Gene expression for OPN, collagen type I (COL I), BSP, and OCN was determined by Northern analysis. An I 8 S probe was used to evaluate loading efficiency and for normalization. Importantly, at this time point, follicle cells express markers for mineralized tissues, BSP, and OCN. EMD enhanced expression of transcripts for COL I and OPN, but only for cells treated with EMD + AA compared to AA alone. Further, EMD enhanced BSP MRNA, while downregulating OCN expression by follicle cells. B. Normalization expressed as gene/ / $8 \mathrm{~S}$ mRNA. These results were noted in 2 separate experiments ( $Y$ axis: relative value treated/control).

pared with controls, 2\% FBS plus AA (Fig. 5). Further, enhanced collagen expression was noted in EMDtreated cells versus $2 \%$ FBS alone. The ability of EMD to enhance BSP mRNA, noted at day 12, was not apparent at this time point. In contrast, by day 18 , cells exposed to EMD exhibited minimal expression for OCN mRNA independent of the presence/absence of ascorbic acid.

Mineralization. SVF cells were capable of inducing mineralization by day 18 , with greater mineral nodule formation noted by day 24 . EMD blocked SVF cell-mediated mineralization in vitro (Fig. 6).

\section{DISCUSSION}

Tooth organogenesis (formation of enamel and dentin) is dependent on reciprocal and sequential epithelial-mesenchymal interactions, and this process is marked by the appearance of specific matrix macromolecules. ${ }^{38}$ In contrast, the mechanisms and cells regulating cementum-periodontal formation remain undefined. Histological investigations of periodontal development suggest that ectomesenchymal cells; that is, dental papillae and dental follicle cells, when triggered, appropriately secrete the matrix required for their differentiation into cementoblasts, osteoblasts, and periodontal ligament cells. ${ }^{39}$ More recent studies provide evidence that the trigger factors may be derived from surrounding epithelial cells, thus suggesting that epithelial-mesenchymal interactions are important for formation of the periodontium. ${ }^{11,26}$

The present study focused on isolating and characterizing follicle cells in vitro and determining their interaction with enamel matrix proteins. The dental follicle tissue contains a heterogeneous population of mesenchymal cells, where Ten Cate and Mills suggested that the dental follicle gives rise to cementum, periodontal ligament, and bone. ${ }^{40}$ In their studies, they transplanted tooth germs of hamster and mice to subcutaneous sites in host animals and, by using tritiated thymidine, demonstrated that the newly formed cementum and periodontal ligament were derived from the transplanted tissues. ${ }^{40}$ As an extension of these studies, Yoshikawa and Kollar ${ }^{41}$ and Palmer and Lums$\operatorname{den}^{42}$ separated various parts of the murine tooth 


\section{Day 18}

$\mathbf{A}$

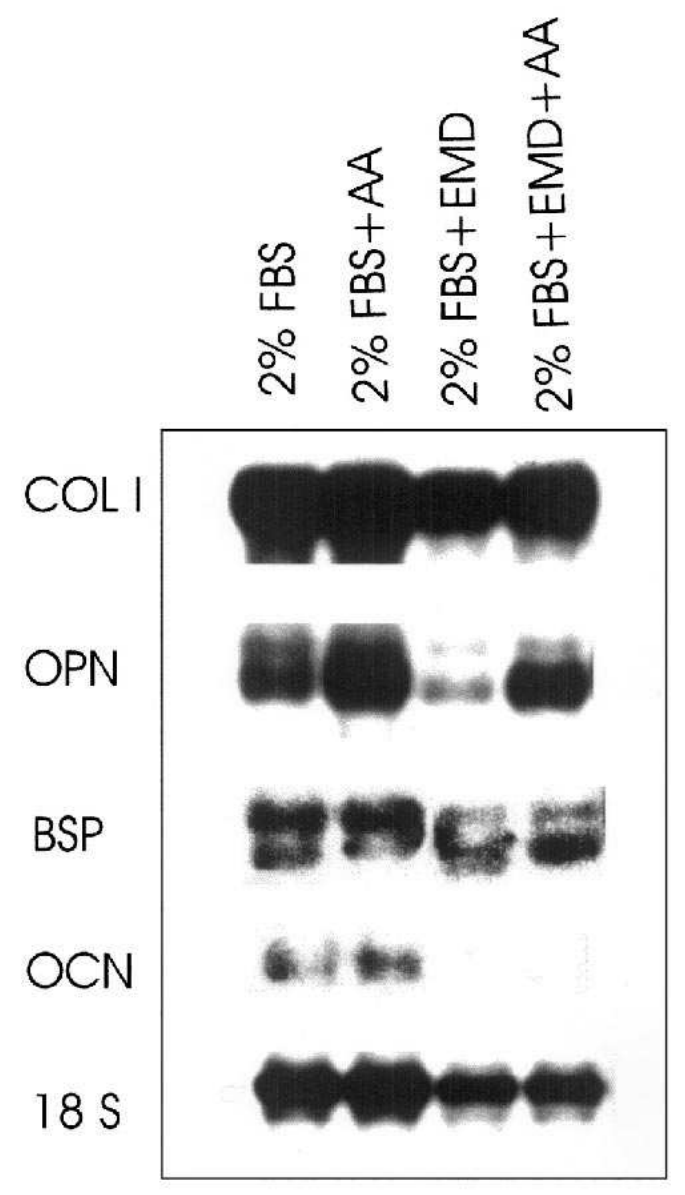

B
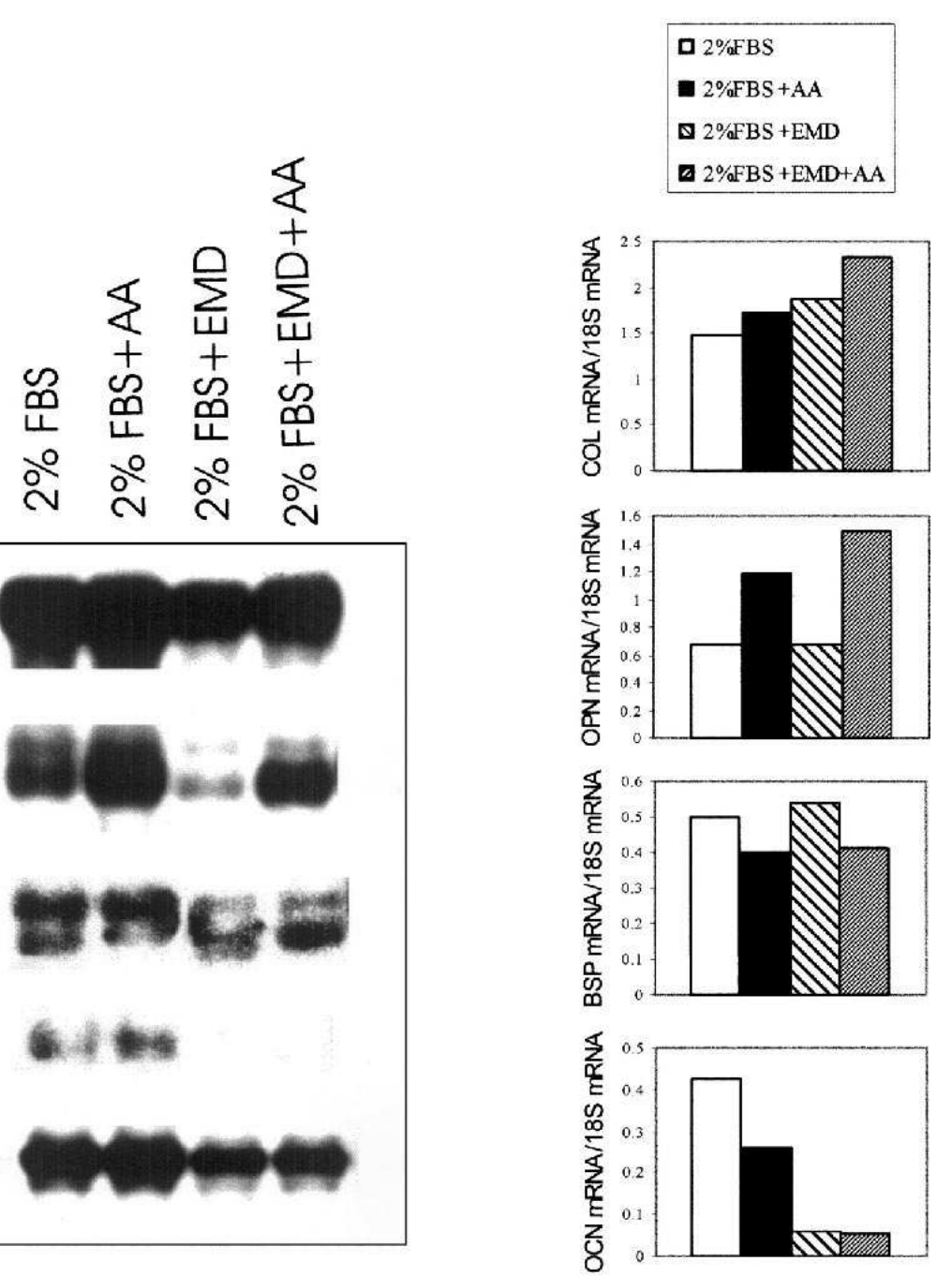

Figure 5.

Effect of EMD on gene expression by follicle cells on day 18. A. Follicle cells were grown in media containing $2 \% F B S \pm A A$ and $\pm E M D$ and RNA isolated at day 18. Gene expression for OPN, collagen type I (COL I), BSP, and OCN was determined by Northern analysis. An I8S probe was used to evaluate loading efficiency and for normalization. At this time point, EMD retained the ability to promote OPN (+ AA only) and COL I $( \pm A A)$ gene expression, while EMD had minimal effect on BSP mRNA. In contrast, EMD, with or without AA, significantly downregulated OCN expression. B. Normalization expressed as gene/I 8 S mRNA. These results were noted in 2 separate experiments (Y axis: relative value treated/control).

germ, i.e., enamel organ, dental follicle, and papilla, and used various recombinations of these tissues for transplantation into the eye of host animals. These studies supported the concept that follicle tissues are critical for formation of both cementum and bone. The results from the in vitro studies reported here, demonstrating that follicle cells have the capacity to induce mineralization and also to express gene markers asso- ciated with the cementoblast and osteoblast phenotype, support these conclusions.

Importantly, in our studies, when follicle cells were first isolated, they did not express markers of the mature cementoblast/osteoblast phenotype, paralleling the findings from our in situ investigations. ${ }^{28,29}$ The fact that, with time in culture, follicle cells express BSP and OCN transcripts suggests that a specific population of cells, not detected in situ, were selected out or alternatively, that cells, with time, begin to secrete a matrix that supports differentiation along the cementoblast/osteoblast pathway. Recently, Hou et al. ${ }^{43}$ demonstrated that follicle cells in vitro, isolated from day 25 mice tissue, express type I and III collagen, fibronectin, and alkaline phosphatase. Also, using in situ hybridization, they reported BSP and OPN gene expression at this time point in cells within the developing root region and also surrounding alveolar bone, but not within the follicle region. It was not clear whether the cultured cells expressed transcripts for OPN and BSP. Nevertheless, their data, coupled with our findings and past recombination studies, provide strong evidence that follicle cells have the capacity to function as cementoblasts/osteoblasts.

Having demonstrated that these cells express markers associated with mature osteoblasts and cementoblasts, we were interested in determining whether enamel matrixderived proteins had the ability to alter follicle cell gene expression and induction of biomineralization in vitro. As reported previously for human periodontal ligament cells, preosteoblast calvaria cell line (OCT-1), osteoprogenitor cell line (MC3T3E1), and cementoblasts (OC-CM), ${ }^{14,31}$ EMD promoted proliferation of follicle cells. Since many factors that promote proliferation inhibit cell maturation, the effect of EMD on gene expression and mineral nodule formation by follicle cells was determined. In the absence of EMD, SVF cells were capable of inducing mineralization on day 18 (Fig. 6). EMD has been shown to inhibit cementoblast-mediated mineral nodule forma- 


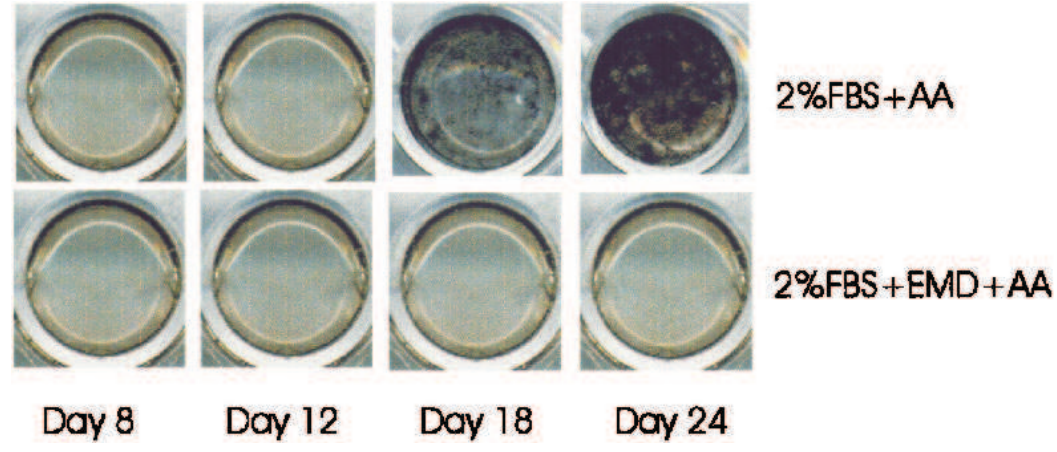

Figure 6.

Induction of mineralization by follicle cells in vitro. For these studies, cells were cultured in media containing $2 \% F B S, 50 \mu \mathrm{g} / \mathrm{ml} \mathrm{AA}, 10 \mathrm{mM} \beta$-glycerophosphate, and EMD at $100 \mu \mathrm{g} / \mathrm{ml}$. On days 8, 12, 18, and 24, von Kossa staining was performed to determine mineral nodule formation. Follicle cells started to induce mineralization by day 18. Note increased mineral nodule formation on day 24. EMD blocked follicle cellmediated mineral nodule formation, and this effect was noted at both day 18 and

day 24. These results were noted in 3 separate experiments.

$\mathrm{OCN}$ is specific to mineralized tissues and is an early marker for cells undergoing mineralization. In addition, there is accumulating evidence that OCN controls crystal growth. ${ }^{45}$ Osteocalcin-deficient mice provide evidence that OCN inhibits bone formation, but not dentin formation, by preventing bone matrix deposition by osteoblasts. ${ }^{46}$ BSP and OPN, both adhesion molecules containing RGD domains, have been implicated as having a role in regulating the migration and attachment of cells to the local site. In terms of cementum formation, it is possible that both of these molecules promote adhesion of cells onto the root surface as required for cementum formation. BSP, a mineral-selective molecule, also is implicated as having a key role in promoting biomineralization. ${ }^{47}$ In contrast, while OPN is found in high concentrations in mineralized tissues, it is also found in several other tissues and has been assigned various

tion. ${ }^{31}$ Consistent with these findings, in this study, EMD totally blocked follicle cell-mediated mineral nodule formation in vitro. In contrast to the studies here, Gestrelius et al. showed that EMD promoted periodontal ligament-mediated mineral formation. ${ }^{19}$ There are several possibilities for these discrepancies, including differences in cell types, species, and experimental design. The specific mechanisms by which EMD decreased mineral nodule formation requires further investigation. However, it is tempting to speculate that EMD's effect on mineral formation is related to the evidence that EMD enhances the expression of transforming growth factor (TGF) $-\beta .^{27}$ Several laboratories have shown that TGF- $\beta$ inhibits cell-mediated mineral nodule formation in vitro. ${ }^{44}$ Thus, the data here suggest that some products from the surrounding epithelial cells promote cell proliferation, providing a critical mass of cells required for promoting mineralized tissue formation; i.e., tooth root cementum and alveolar bone, but that such products may also regulate the extent of mineral formation and allow for development of the periodontal ligament.

In parallel with determining the effects of EMD on mineral nodule formation, the influence of EMD on gene expression by follicle cells was assessed. The most significant finding was the dramatic decrease in OCN mRNA levels in EMD-treated follicle cells when compared with $2 \%$ FBS control, as previously noted for cementoblasts $^{31}$ (Figs. 4 and 5). In addition, there was also an increase in OPN expression at all time points, with an increase in BSP transcripts noted at day 12 . In translating these in vitro findings into possible clinical implications, it is important to review the activities attributed to OCN, BSP, and OPN. While the exact role for OCN in the mineralization process is unknown, functions. In terms of mineralized tissues, OPN may serve as a regulator of crystal growth. ${ }^{48}$

Thus, based on the putative roles for OPN, BSP, and OCN during mineralization, one might have anticipated increased mineralization with the dramatic decrease in OCN expression. There are several plausible explanations for this finding, including the fact that there are most likely several proteins controlling the mineralization process and that EMD is capable of regulating many of these factors, e.g., TGF- $\beta$ as discussed above, where the relative concentration of specific factors determines the extent of mineralization.

Translating these results to the clinical level, it is clear that EMD influence cell activities, where a fundamental activity of EMD is to promote cell proliferation. Thus, the time EMD remains at a site, coupled with the cells that have been triggered by EMD, most likely determines the clinical outcome. In an ideal situation, EMD may provide the critical cell mass for promoting bonecementum formation, while regulating crystal growth, allowing for formation of a periodontal ligament. Clearly, further investigations are required to identify the exact role of follicle cells during development and to determine the specific factors controlling follicle cell activities during development. Identifying these factors should provide information necessary to design knowledge-based regenerative periodontal therapies.

\section{ACKNOWLEDGMENTS}

The authors thank Bev Sutton for assistance in preparing the manuscript and Dr. Ming Zhao for performing the immunohistochemical assays for cytokeratins and TAg. This study was supported by NIDCR grant DE09532 and the Scientific and Technical Research Council of Turkey. 


\section{REFERENCES}

1. Wise GE, Lin F, Fan W. Culture and characterization of dental follicle cells from rat molars. Cell Tissue Res 1992;267:483-492.

2. Wise GE, Lin F, Zhao L. Transcription and translation of CSF-1 in the dental follicle. J Dent Res 1995;74:15511557 (erratum: J Dent Res 1995;74:1722.)

3. Cahill DR, Marks SC Jr. Tooth eruption: Evidence for the central role of the dental follicle. J Oral Pathol 1980;9:189-200.

4. Grier RLt, Zhao L, Adams CE, Wise GE. Secretion of CSF1 and its inhibition in rat dental follicle cells: Implications for tooth eruption. Eur J Oral Sci 1998;106:808-815.

5. Larson EK, Cahill DR, Gorski JP, Marks SC Jr. The effect of removing the true dental follicle on premolar eruption in the dog. Arch Oral Biol 1994;39:271-275.

6. Sakakura Y, Yajima T, Tsuruga E. Confocal laser scanning microscopic study (corrected) of tartrate-resistant acid phosphatase-positive cells in the dental follicle during early morphogenesis of mouse embryonic molar teeth. Arch Oral Biol 1998;43:353-360 (erratum: Arch Oral Biol 1998;43:751).

7. MacNeil RL, Somerman MJ. Development and regeneration of the periodontium: Parallels and contrasts. Periodontol 2000 1999;19:8-20.

8. Saygin N, Giannobile WV, Somerman MJ. Molecular and cell biology of cementum. Periodontol 2000 2000;24:7398.

9. Thesleff I, Vaahtokari A, Vainio S, Jowett A. Molecular mechanisms of cell and tissue interactions during early tooth development. Anat Rec 1996;245:151-161.

10. Hammarström L, Alatli I, Fong CD. Origins of cementum. Oral Dis 1996;2:63-69.

11. Fong CD, Slaby I, Hammarström L. Amelin: An enamelrelated protein, transcribed in the cells of epithelial root sheath. J Bone Miner Res 1996;11:892-898.

12. Bosshardt DD, Selvig KA. Dental cementum: The dynamic tissue covering of the root. Periodontol 2000 1997;13:41-75.

13. Nanci A, Kawaguchi H, Kogaya Y. Ultrastructural studies and immunolocalization of enamel proteins in rodent secretory stage ameloblasts processed by various cryofixation methods. Anat Rec 1994;238:425-436.

14. Gestrelius S, Andersson C, Johansson AC, et al. Formulation of enamel matrix derivative for surface coating. Kinetics and cell colonization. J Clin Periodontol 1997;24:678-684.

15. Lyngstadaas SP, Risnes S, Sproat BS, Thrane PS, Prydz HP. A synthetic, chemically modified ribozyme eliminates amelogenin, the major translation product in developing mouse enamel in vivo. Embo $J$ 1995;14:52245229.

16. Fincham AG, Moradian-Oldak J, Diekwisch TG, et al. Evidence for amelogenin "nanospheres" as functional components of secretory-stage enamel matrix. J Struct Biol 1995; 115:50-59.

17. Takagi Y, Fujita H, Katano H, Shimokawa H, Kuroda T. Immunochemical and biochemical characteristics of enamel proteins in hypocalcified amelogenesis imperfecta. Oral Surg Oral Med Oral Pathol Oral Radiol Endod 1998;85:424-430.

18. van der Pauw MT, van den Bos T, Everts V, Beertsen W. Enamel matrix-derived protein stimulates attachment of periodontal ligament fibroblasts and enhances alkaline phosphatase activity and transforming growth factor beta release of periodontal ligament and gingival fibroblasts. $J$ Periodontol 2000;71:31-43.
19. Gestrelius S, Andersson C, Lidstrom D, Hammarström L, Somerman M. In vitro studies on periodontal ligament cells and enamel matrix derivative. $J$ Clin Periodontol 1997;24:685-692.

20. Heijl L, Heden G, Svardstrom G, Ostgren A. Enamel matrix derivative (EMDOGAIN) in the treatment of intrabony periodontal defects. J Clin Periodontol 1997;24: 705-714.

21. Heijl L. Periodontal regeneration with enamel matrix derivative in one human experimental defect. A case report. J Clin Periodontol 1997;24:693-696.

22. Zetterstrom O, Andersson C, Ericksson L, et al. Clinical safety of enamel matrix derivative (EMDOGAIN) in the treatment of periodontal defects. J Clin Periodontol 1997; 24:697-704.

23. Heden G, Wennstrom J, Lindhe L. Periodontal tissue alterations following Emdogain treatment of periodontal sites with angular bone defects. A series of case reports. J Clin Periodontol 1999;26:855-860.

24. Pontoriero R, Wennstrom J, Lindhe J. The use of barrier membranes and enamel matrix proteins in the treatment of angular bone defects. A prospective controlled clinical study. J Clin Periodontol 1999;26:833-840.

25. Sculean A, Reich E, Chiantella GC, Brecx M. Treatment of intrabony periodontal defects with an enamel matrix protein derivative (Emdogain): A report of 32 cases. Int J Periodontics Restorative Dent 1999;19:157-163.

26. Hammarström L, Heijl L, Gestrelius S. Periodontal regeneration in a buccal dehiscence model in monkeys after application of enamel matrix proteins. J Clin Periodontol 1997;24:669-677.

27. Lyngstadaas S, Lundberg E, Ekdahl H, Anderson C, Gestrelius S. Increased TGF-beta production in PDL cells grown on EMDOGAIN matrix. J Dent Res 1999;78(Spec. Issue):189(Abstr. 671).

28. MacNeil RL, Berry JE, Strayhorn CL, Somerman MJ. Expression of bone sialoprotein mRNA by cells lining the mouse tooth root during cementogenesis. Arch Oral Biol 1996;41:827-835.

29. MacNeil RL, Sheng N, Strayhorn CL, Fisher LW, Somerman MJ. Bone sialoprotein is localized to the root surface during cementogenesis. J Bone Miner Res 1994;9: 1597-1606.

30. Chen D, Chen H, Feng JQ, et al. Osteoblastic cell lines derived from a transgenic mouse containing the osteocalcin promoter driving SV40 T-antigen. Mol Cell Differentiation 1995;3:193-212.

31. Tokiyasu Y, Saygin NE, Somerman MJ. Enamel factors regulate expression of genes associated with cementoblasts. J Periodontol 2000;71:1829-1839.

32. Young MF, Ibaraki K, Kerr JM, Lyu MS, Kozak CA. Murine bone sialoprotein (BSP): cDNA cloning, mRNA expression, and genetic mapping. Mamm Genome 1994; 5:108-111.

33. Young MF, Kerr JM, Termine JD, et al. cDNA cloning, mRNA distribution and heterogeneity, chromosomal location, and RFLP analysis of human osteopontin (OPN). Genomics 1990;7:491-502.

34. Celeste AJ, Rosen V, Buecker JL, Kriz R, Wang EA, Wozney JM. Isolation of the human gene for bone gla protein utilizing mouse and rat cDNA clones. Embo $J$ 1986;5:1885-1890.

35. D'Errico JA, Ouyang H, Berry JE, et al. Immortalized cementoblasts and periodontal ligament cells in culture. Bone 1999;25:39-47.

36. Franceschi RT, Iyer BS, Chi Y. Effects of ascorbic acid on collagen matrix formation and osteoblast differenti- 
ation in murine MC3T3-E1 cells. J Bone Miner Res 1994;9:843-854.

37. Puchtler H, Meloan SN. Demonstration of phosphates in calcium deposits: A modification of von Kossa's reaction. Histochem 1978;56:177-185.

38. Bleicher F, Couble ML, Farges JC, Couble P, Magloire $\mathrm{H}$. Sequential expression of matrix protein genes in developing rat teeth. Matrix Biol 1999;18:133-143.

39. Ten Cate AR, Mills C, Solomon G. The development of the periodontium. A transplantation and autoradiographic study. Anat Rec 1971;170:365-379.

40. Ten Cate AR, Mills C. The development of the periodontium: The origin of alveolar bone. Anat Rec 1972; 173:69-77.

41. Yoshikawa DK, Kollar EJ. Recombination experiments on the odontogenic roles of mouse dental papilla and dental sac tissues in ocular grafts. Arch Oral Biol 1981; 26:303-307.

42. Palmer RM, Lumsden AG. Development of periodontal ligament and alveolar bone in homografted recombinations of enamel organs and papillary, pulpal and follicular mesenchyme in the mouse. Arch Oral Biol 1987; 32:281-289.

43. Hou LT, Liu CM, Chen YJ, et al. Characterization of dental follicle cells in developing mouse molar. Arch Oral Biol 1999;44:759-770.

44. McCauley LK, Somerman MJ. Biologic modifiers in periodontal regeneration. Dent Clin North Am 1998;42:361 387.

45. Ducy P. Skeletal Gla proteins: Gene structure, regulation of expression, and function. In: Bilezikian JP, Raisz LG, Rodan GA, eds. Principles of Bone Biology. San Diego: Academic Press; 1996:183-196.

46. Ducy P, Desbois C, Boyce B, et al. Increased bone formation in osteocalcin-deficient mice. Nature 1996;382: 448-452.
47. Hunter GK, Goldberg HA. Modulation of crystal formation by bone phosphoproteins: Role of glutamic acidrich sequences in the nucleation of hydroxyapatite by bone sialoprotein. Biochem J 1994;302:175-179.

48. Butler WT, Ridall AL, McKee MD. Osteopontin. In: Bilezikian JP, Raisz LG, Rodan GA, eds. Principles of Bone Biology. San Diego: Academic Press; 1996:167182.

Send reprint requests to: Dr. Martha J. Somerman, Department of Periodontics, Prevention and Geriatrics, University of Michigan, School of Dentistry, 1011 N. University Ave., Ann Arbor, MI 48109-1078. Fax: 734/763-5503; email: somerman@umich.edu

Accepted for publication December 15, 2000. 